\title{
On the Valuation of Investment Guarantees in Unit-linked Life Insurance: A Customer Perspective
}

\author{
Nadine Gatzert ${ }^{\mathrm{a}}$, Carin Huber $^{\mathrm{b}}$ and Hato Schmeiser ${ }^{\mathrm{b}}$ \\ ${ }^{a}$ University of Erlangen-Nürnberg, Chair for Insurance Economics, Lange Gasse 20, 90403 Nuremberg, \\ Germany. \\ E-mail: nadine.gatzert@wiso.uni-erlangen.de \\ ${ }^{\mathrm{b}}$ Institute of Insurance Economics, University of St. Gallen, Kirchlistrasse 2, St. Gallen, SG 9010, \\ Switzerland. \\ E-mails: carin.huber@unisg.ch, hato.schmeiser@unisg.ch
}

Interest rate guarantees in unit-linked life insurance products ensure that at contract maturity, at least a minimum guaranteed amount is paid, even if the mutual fund falls below the guaranteed level. Strongly depending on the riskiness of the underlying mutual fund, these guarantees can be of substantial value. However, while insurer pricing is based on the replication of cash flows, customers are more likely to base their decisions on individual preferences. The aim of this paper is to contrast reservation prices for guarantees in unit-linked life insurance policies based on customers' subjective willingness to pay with a financial pricing approach, an investigation that has not been undertaken to date. To do so, we use an online questionnaire survey and calculate reservation prices using option pricing theory. Our findings reveal that even though the majority of the participants in the online questionnaire are employed in the field of insurance, subjective prices are difficult to derive and are significantly lower on average than the prices obtained using a financial pricing model. However, a considerable portion of participants is still willing to pay a substantially higher price.

The Geneva Papers (2011) 36, 3-29. doi:10.1057/gpp.2010.35

Keywords: behavioural insurance; investment guarantees; unit-linked life insurance; willingness to pay; empirical survey

\section{Introduction}

Attractive pension product design is becoming increasingly important, in part due to demographic changes (i.e., the increasing number of elderly people and the ageing of the population) in many countries. For this reason, knowing customer perceptions and preferences as to product characteristics is crucial for product development. Unitlinked life insurance policies, in particular, are often offered with different types of investment guarantees, typically ensuring that at least a minimum amount is paid, even if the mutual fund value falls below a specific guaranteed level. These guarantees can be of substantial value since - depending on the riskiness of the underlying fundcostly risk management measures must be undertaken to secure the guarantees promised to the customers. Thus, the question arises as to whether customers' maximum willingness to pay (WTP) actually exceeds the reservation price, which is the minimum amount an insurer needs to charge in order to buy adequate risk 
management measures to ensure the guarantee. The reservation price is thus the minimum price at which an insurer is willing to sell a guarantee. In the following analysis, the reservation price is based on model assumptions, such as no transaction costs and no jumps, and may thus be higher in practice.

The aim of this paper is to broaden the traditional viewpoint of risk valuation of investment guarantees in unit-linked life insurance products and to investigate the difference between customer WTP for investment guarantees and the insurer's reservation price for a guarantee. This will be done by comparing the results from an empirical survey with those of a financial valuation approach. In general, examining WTP and the process of decision-making requires psychological foundations in order to consider possible biases or heuristics. These have been broadly studied in the field of behavioural economics, which has led to the development of new theoretical models, such as prospect theory, ${ }^{1}$ cumulative prospect theory ${ }^{2}$ and the model of intertemporal choice. $^{3}$

Experimental analyses of insurance demand build on and complement important previous empirical studies on behavioural economics. Wakker et al. ${ }^{4}$ use prospect theory, developed by Kahneman and Tversky ${ }^{1}$ to explain experimental data on the demand for probabilistic insurance. A probabilistic insurance policy indemnifies the policy-holder with a probability of strictly less than 1 to account for insurer default risk. Other recent experimental research on demand for insurance under default risk has been conducted by Albrecht and Maurer ${ }^{5}$ and Zimmer et al., ${ }^{6}$ who show that awareness of even a very small positive probability of insolvency drastically reduces customer WTP. Gatzert et al. ${ }^{7}$ contrast prices for participating life insurance contracts determined via financial theory with prices determined via expected utility theory, thus combining customer and insurer perspectives based on theoretical valuation models. In particular, contract parameter combinations are identified that-while keeping the contract value fixed and fair from the insurer's viewpoint-maximise customer value. However, in contrast to this paper, Gatzert et al. ${ }^{7}$ do not focus on an empirical analysis in order to analyse how customers evaluate life insurance contracts in general and the value of investment guarantees in particular.

Previous literature on behavioural insurance has focused on the impact of insurance company insolvency risk on customer WTP. We extend this research by investigating customer WTP to prevent their maturity payoff from falling below a fixed guaranteed level. In addition, we contrast these results with the actual reservation price that, from the insurer's perspective, is necessary to acquire risk management measures that will ensure the investment guarantee. To the best of our knowledge, this paper is the first to study the gap between the value of guarantees in unit-linked life insurance based on duplication of cash flow (from the insurer perspective) and the empirically identified

\footnotetext{
${ }^{1}$ Kahneman and Tversky (1979).

2 Tversky and Kahneman (1992).

${ }^{3}$ Loewenstein and Prelec (1992).

${ }^{4}$ Wakker et al. (1997).

${ }^{5}$ Albrecht and Maurer (2000).

${ }^{6}$ Zimmer et al. (2008, 2009).

${ }^{7}$ Gatzert et al. (2009).
} 
value of guarantees from the customer perspective. The present analysis is a first step in discovering customer WTP for investment guarantees in unit-linked life insurance contracts. On the basis of research (e.g., Wakker et al., ${ }^{4}$ Zimmer et al. ${ }^{6}$ ) examining WTP for insurance products with default probability, we try to avoid making people sensitive to the problem of default risk, as it can be presumed that many customers may not consider default risk in their insurance purchase decisions at all. We assume that our provided method of asking WTP for an investment guarantee will be more realistic from a practitioner's point of view. Furthermore, participants will have the option to choose or to refuse the guarantee, as insurance products are seen as product bundles, where it is possible to buy an additional guarantee or not.

We provide an empirical framework that combines the insurer and customer viewpoints in the context of unit-linked life insurance contracts with an embedded investment guarantee. In a first step, we calculate the fair price of an investment guarantee in a unit-linked insurance contract, which is the reservation price the insurance company needs to charge in order to secure the guarantee with risk management measures. In a second step, we conduct a comprehensive survey to identify customer WTP for investment guarantees. We take into account customers' gender, age, financial background knowledge and risk behaviour. In the empirical design, customer WTP for guarantees might exceed or fall below the insurer's calculated reservation price.

The remainder of the paper is organised as follows. In the next section, the unit-linked life insurance contract design with minimum interest rate guarantee is introduced and evaluated from the insurer's perspective using risk-neutral valuation. The section after that presents the customer's perspective, along with survey design and empirical results on WTP for guarantees from the customer's perspective using descriptive statistics and different statistical tests. The subsequent section derives policy implications based on the empirical findings, and the last section provides a summary and an outlook for future research fields.

\section{Risk-neutral valuation of investment guarantees in unit- linked life insurance products}

Unit-linked life insurance contracts typically contain a savings policy and a death benefit that is paid out if the policy-holder dies during the term of the contract. In respect to the savings part of the contract, one common form of underlying is a mutual fund with an embedded investment guarantee. A single up-front premium paid by the policy-holder for a unit-linked life insurance contract can be split into two parts: the premium $P^{d}$ for the death benefit and $P$ for the savings policy. In the following, we focus on the value of investment guarantees in unit-linked life policies only, and study this value from both the insurer's and the customer's perspective. Thus, death benefits or transaction costs are not included in the model, and the focus is solely on the savings part of the product. To simplify our questionnaire (described in detail in the section 'The value of investment guarantees from the customer perspective'), mortality risk (i.e., the chance that the policy-holder will die before the contract matures), the possibility of early option exercise (e.g., surrendering the contract) and the use of a paid-up option are not included in the model framework. 


\section{Design and modelling of the underlying mutual funds}

To determine a risk-adequate price for investment guarantees included in unit-linked life insurance contracts, we use the following model framework. ${ }^{8}$ At time $t=0$, the policy-holder pays a single up-front premium $P$ that is invested in a traded mutual fund with a contract term of $T$ years. The unit price of the mutual fund at time $t$ is denoted by $S_{t}$ and its development is described by a geometric Brownian motion with fixed average rate of return and standard deviation during the policy term. Hence, under the objective (or empirical) measure $\mathbb{P}$, it can be described by the following stochastic differential equation,

$$
d S_{t}=S_{t}\left(\mu d t+\sigma d W_{t}\right)
$$

with $S_{0}=S(0)$, a constant drift $\mu$, a volatility $\sigma$ and a standard $\mathbb{P}$-Brownian motion $\left(W_{t}\right), 0 \leqslant t \leqslant T$, on a probability space $(\Omega, \mathcal{F}, \mathbb{P})$. In addition, $\left(\mathcal{F}_{t}\right), 0 \leqslant t \leqslant T$, denotes the filtration generated by the Brownian motion. The solution of the stochastic differential equation is given by ${ }^{9}$

$$
\begin{aligned}
S_{t} & =S_{t-1} \cdot e^{\left(\mu-\sigma^{2} / 2\right)+\sigma\left(W_{t}-W_{t-1}\right)} \\
& =S_{t-1} \cdot e^{\left(\mu-\sigma^{2} / 2\right)+\sigma Z_{t}}=S_{t-1} \cdot R_{t},
\end{aligned}
$$

where $Z_{t}$ are independent standard normally distributed random variables. Hence, the continuous one-period return $r_{t}=\ln \left(R_{t}\right)$ is normally distributed with an expected value of $\mu-\sigma^{2} / 2$ and standard deviation $\sigma$.

\section{Mutual fund payoff with embedded investment guarantee}

At maturity, the stochastic value of the investment at maturity $T, F_{T}$, is given by the number of acquired units $\left(P / S_{0}\right)$ times the value $S_{T}$ of a unit in $T$ :

$$
F_{T}=\frac{P}{S_{0}} \cdot S_{T}
$$

The payoff depends on the fund's development over time and thus on future conditions in the financial market. Therefore, the terminal value of the investment can fall below the initially paid premium $P$. To prevent such a default situation for the policy-holder, unit-linked life insurance contracts are often offered with an interest rate guarantee $g$ on premium $P$, providing a minimum payoff $G_{T}$ of the investment at maturity $T$. In formal terms, $G_{T}$ is given by:

$$
G_{T}=P \cdot \exp (g \cdot T)
$$

\footnotetext{
${ }^{8}$ See, for example, Gatzert and Schmeiser (2009) and Lachance and Mitchell (2003).

${ }^{9}$ See, for example, Björk (2004).
} 
In the presence of an investment guarantee, the customer's terminal payoff is the greater of the guaranteed minimum payoff $G_{T}$ and the value of the investment in the underlying fund, that is,

$$
L_{T}=\max \left(F_{T}, G_{T}\right)=F_{T}+\max \left(G_{T}-F_{T}, 0\right) .
$$

The right-hand side of Eq. (1) shows that the payoff to the investor at maturity, $L_{T}$, can be written as the value of the underlying assets $\left(F_{T}\right)$ at time $T$ plus a put option on $F_{T}$ with a strike price $G_{T}$ (guaranteed minimum payoff).

\section{Default probabilities for $F_{T}<G_{T}$}

Under the given assumptions, $\ln \left(F_{T}\right)$ is normally distributed with mean $m=\ln (P)+$ $\left(\mu-\sigma^{2} / 2\right) T$ and standard deviation $v=\sigma \cdot \sqrt{ } T$. Hence, the probability that the value of the mutual fund at maturity, $F_{T}$, is below the guaranteed level $G_{T}$ can be calculated in the following way: ${ }^{10}$

$$
\operatorname{Pr}\left(F_{T}<G_{T}\right)=N\left(\frac{\ln \left(G_{T}\right)-m}{v}\right),
$$

where $N(\cdot)$ denotes the cumulative probability distribution function for a standard normal distribution. The probability that $F_{T}<G_{T}$ and hence the provider of the investment guarantee has to pay the difference between $G_{T}$ and $F_{T}$ to the customer is given in Table 3 for different numerical examples (see Figures 1-5 and Tables 1-8).

\section{Valuation of investment guarantee from the insurer's perspective}

The value of the investment guarantee from the insurer's perspective is derived by using the concept of risk-neutral valuation. The cost of the guarantee is the reservation (or minimum) price an insurer needs to charge at time $t=0$, in addition to the premium that is invested in the mutual fund, to be able to finance adequate risk management measures. Such risk management measures (e.g., hedging strategies, equity capital or reinsurance) must ensure the guarantee provided to the policy-holder.

Under the unique equivalent martingale measure $\mathbb{Q},{ }^{11}$ the development of the unit price of the mutual funds at time $t, S_{t}$, is given by

$$
d S_{t}=S_{t}\left(r d t+\sigma d W_{t}^{\mathbb{Q}}\right)
$$

where $W^{\mathbb{Q}}$ is a standard $\mathbb{Q}$-Brownian motion. Compared to the description of the mutual fund unit price process under the objective measure $\mathbb{P}$, the drift $\mu$ changes to the riskless rate of return $r$. The value of the investment guarantee $\Pi_{0}^{G}$ at time $t=0$ is then given as the difference between the present value of the contract's payoff under

\footnotetext{
${ }^{10}$ See, for example, Winkler et al. (1972, pp. 290-295).

${ }^{11}$ See Harrison and Kreps (1979).
} 
the risk-neutral measure $\mathbb{Q}$ and the present value of the premiums paid, discounted with the riskless interest rate $r$. According to Eq. (1), this implies that the price of the investment guarantee $\Pi_{0}^{G}$ is the price of a European put option with strike $G_{T}$. Using the Black and Scholes option pricing formula, one obtains. ${ }^{12}$

$$
\begin{aligned}
\Pi_{0}^{G} & =e^{-r T} \cdot E^{\mathbb{Q}}\left(\max \left(G_{T}-F_{T}, 0\right)\right) \\
& =G_{T} \cdot e^{-r T} \cdot N\left(-d_{2}\right)-P \cdot N\left(-d_{1}\right)
\end{aligned}
$$

where $N(\cdots)$ denotes the cumulative probability distribution function for a standard normal distribution and

$$
\begin{aligned}
& d_{1}=\frac{\ln \left(\frac{P}{G_{T}}\right)+\left(r+\frac{\sigma^{2}}{2}\right) \cdot T}{\sigma \cdot \sqrt{T}}, \\
& d_{2}=\frac{\ln \left(\frac{P}{G_{T}}\right)+\left(r-\frac{\sigma^{2}}{2}\right) \cdot T}{\sigma \cdot \sqrt{T}}=d_{1}-\sigma \cdot \sqrt{T} .
\end{aligned}
$$

The price of the guarantee calculated in Eq. (2) rather represents a lower limit to the market price, since no transaction costs are included.

\section{The value of investment guarantees from the customer's perspective}

The value of guarantees in unit-linked life insurance contracts may differ depending on the perspective from which they are viewed. On the one hand, an insurer is generally able to calculate the appropriate premium for investment guarantees assuming a duplication of the cash flows, such as risk-neutral valuation and other premium principles, all based on the assumption of an efficient capital market. Customers, on the other hand, are not necessarily able to replicate cash flows or claims to the same extent as the insurer, and may thus assess the value of investment guarantees based on their own preferences. In addition, it may not be appropriate to assume a homo economicus when it comes to subjective WTP. Thus, customer WTP may be quite different from what financial theory suggests. To elicit customer WTP, we conduct a survey, explained below.

\section{Design of the survey}

The aim of the study is to compare objective (model-based) and subjective (assessed by the survey) prices for guarantees that are included in unit-linked life insurance products. To elicit the subjective WTP, we used a computer-based questionnaire comprising direct open-response questions, a section containing choice options and questions about the respondent's demographic characteristics or knowledge about insurance. An overview of methods for measuring consumer WTP can be found in

12 See, for example, Hull (2008, p. 291). 
Miller et al. ${ }^{13}$ or Diller. ${ }^{14}$ In this study, we use a direct survey method. Even though measuring WTP directly in general has a lack of validity and reliability ${ }^{15,16}$ and thus the results and implications will only be tentative, we assume that it will be a feasible approach, particularly due to the specific sample with finance or insurance background. In addition to measuring WTP, a direct approach provides first insights into the understandability of the products and the consumer's price knowledge of investment guarantees in unit-linked life insurance, ${ }^{17}$ which should be of particular interest in the context of pension and insurance products.

Furthermore, examining the value of investment guarantees from the customer perspective needs to consider human behaviour, and thus possible irrational phenomena. We draw on the existing literature of probabilistic insurance (e.g., Wakker et al., ${ }^{4}$ Albrecht and Maurer ${ }^{5}$ or Zimmer et al. ${ }^{6}$ ) and take the following phenomena and biases into account in the questionnaire design:

- Framing effects, that is, reliance on how information is presented, ${ }^{18}$ are dealt with by using graphical, verbal and numerical illustrations of the probabilities (see Figure 3).

- Loss aversion, that is, losses loom larger than corresponding gains, ${ }^{19}$ and overestimation of probabilities ${ }^{20}$ are dealt with by a neutral presentation of possible defaults (see Figure 3).

- Anchoring, that is, the adjustment on an initial value, ${ }^{21}$ is dealt with by the order of the questions (for example, by putting the choice questions with the calculated prices given at the end of the questionnaire) and by not allowing the participants to skip back in the questionnaire.

\section{Empirical study: Input data}

The unit-linked product studied in the survey is based on a mutual fund that invests in bonds and in stocks. The input data for the mutual fund were estimated from the Swiss market indices, with resulting input parameters as shown in Table 1.

In the survey, we compared the case of a "medium-risk" mutual fund that invests 50 per cent in bonds and 50 per cent in stocks with a "high-risk" mutual fund that invests 100 per cent in stocks. The medium-risk fund has an expected return of 4.061 per cent and a volatility $\sigma=8.610$ per cent; the high-risk fund has an expected return of 5.975 per cent and a volatility of $\sigma=17.220$ per cent.

In addition to distinguishing between a medium- and a high-risk fund, we compare three products in the survey: a unit-linked policy without guarantee and two products with guarantees, including a money-back guarantee and a reservation price interest

\footnotetext{
${ }^{13}$ Miller et al. (2010).

${ }^{14}$ Diller (2000).

${ }^{15}$ See, for example, Wertenbroch and Skiera (2002); Breidert et al. (2006) and Völckner (2005).

16 Völckner (2006).

${ }^{17}$ Vanhuele and Drèze (2002).

18 Tversky and Kahneman (1981, 1986); Kahneman and Tversky (1984).

19 Tversky and Kahneman (1991).

${ }^{20}$ Johnson et al. (1993); Slovic (1972); Slovic et al. (1977).

${ }^{21}$ Tversky and Kahneman (1974).
} 
Table 1 Expected value $\left(\mu-0.5 \sigma^{2}\right)$ and standard deviation $(\sigma)$ of annualised continuous returns for selected indices

\begin{tabular}{llcr}
\hline Asset class & Index & $\mu-0.5 \sigma^{2}(\%)$ & $\sigma(\%)$ \\
\hline $\begin{array}{l}\text { Stocks (Swiss) } \\
\text { Bonds (Swiss Money Market) }\end{array}$ & $\begin{array}{l}\text { SMI (Total Return Index) } \\
\text { Yield on bonds of the Swiss } \\
\text { Confederation (duration of 10 years; } \\
\text { period from 1994-2008) }\end{array}$ & 5.975 & 17.220 \\
& & 2.148 & - \\
Portfolios: & Medium-risk fund & & 8.610 \\
$50 \%$ bonds & & 4.061 & 17.220 \\
$100 \%$ stocks & High-risk fund & 5.975 & \\
\hline
\end{tabular}

rate of 2 per cent on the initial nominal premium ( $g=0$ per cent and $g=2$ per cent). Guarantee costs for all three products are calculated based on the Black and Scholes option pricing formula given in Eq. (2).

\section{Sample and survey procedure}

Due to the complexity of investment products and the survey method (directly asking about WTP), we chose a sampling by focusing on participants with some relation to insurance or finance. We assume that insurance and finance professionals are more capable of stating WTP for guarantees directly and are more likely to be familiar with the insurance terminology. The desired sample was achieved by conducting the survey among people in the contact database of the Institute of Insurance Economics at the University of St. Gallen, most of whom work in the financial services industry or in the insurance and finance departments of universities. There are 2,500 people in the contact database. The link to the online questionnaire was sent to each of these individuals via a personal email invitation that contained a unique anonymous login code. Each respondent who chose to participate could complete the questionnaire only once. Once a respondent chose to participate, the goal of the survey was explained and standardised instructions were given without interaction or inducements. Participants filled out the survey individually. Participants could pause the survey, but could not skip questions or go back and change answers. No new question was posed until the current one had been answered. Within the two-week period from 20 May 2009 to 2 June 2009,375 respondents had completed the survey, a completion rate of 14.5 per cent.

The survey was divided into three parts. In the first part, we surveyed participants' demographic characteristics (gender, age, job, education) and some additional information concerning their risk behaviour, stock ownership, knowledge about guarantees in life insurance products and previous purchase of pension or life insurance products (see Figure 1).

To compare theoretical guarantee costs with the price customers are willing to pay, in the second part of the survey, we directly asked the participants their WTP for an additional investment guarantee that would protect them from default at 


\begin{tabular}{|ll|}
\hline 1. Gender & 6. Do you own stocks? \\
$\square$ Male (1) & $\square$ Yes (1) \\
$\square$ Female (2) & $\square$ No (2) \\
& \\
2. Age & 7. Do you know that life insurances \\
$\square$ 18-29 years (1) & generally contain investment guaranties \\
$\square$ 30-45 years (2) & (particularly in the form of reservation \\
$\square$ 46-65 years (3) & price interest rate promises)? \\
$\square$ Over 65 years (4) & $\square$ Yes (1) \\
& $\square$ No (2) \\
3. Job & 8a. Do you own a pension or life \\
$\square$ I work in the area of insurance (1) & insurance product (e.g. pension fund or \\
$\square$ I work in the area of financial services, & life insurance)? \\
but not in insurance (2) & $\square$ No, and signing a contract is not \\
$\square$ I work in a different area (3) & planned either (1) \\
& $\square$ No, but signing a contract is planned \\
4. Did you complete or are you & (2) \\
completing an education, which involves & $\square$ Yes, I own one contract $\quad$ (3) \\
knowledge about financial markets? & $\square$ Yes, I own multiple contracts (4) \\
$\square$ Yes (1) & \\
$\square$ No (2) & 8b. (Only if you answered Question 8a \\
& with “Yes"): Is there a unit-linked life \\
5. How would you describe your risk & insurance product amongst them? \\
behaviour? & $\square$ Yes, one (1) \\
$\square$ Risk averse (1) & $\square$ Yes, multiple (2) \\
$\square$ Risk neutral (2) & $\square$ No (3) \\
$\square$ Risk seeking (3) & $\square$ I don't know (4) \\
&
\end{tabular}

Figure 1. Design of the survey (The survey was originally conducted in German; Figures 1-5 and Tables 1-8 contain translations.)-Part 1: customer characteristics.

Note: Italic numbers in parentheses display coding scheme.

various levels ( $g=0$ per cent, 2 per cent), explaining that the cost of the guarantee would have to be paid in addition to the initial up-front premium invested in the mutual fund (the initial premium was given by $P=\mathrm{CHF} 10,000$, contract term=ten years; see Figures 2-4). The purpose was to investigate the extent to which participants who already have some knowledge about insurance or finance can actually estimate a price they are willing to pay for such a risk management product. To avoid framing effects due to how the payoff was represented (verbally, numerically, graphically, positively or negatively), we made our information about the mutual fund payoff structure as neutral as possible. To this end, participants received a graphical illustration of the terminal payoff and the probabilities accompanied by a written explanation (see Figure 3).

Since direct judgements of guarantee costs are difficult to assess and typically display a high degree of volatility, ${ }^{15}$ in the third part of the survey (see Figure 5), we asked the participants to choose among three products (no guarantee, money-back 
For your retirement provision, you have the possibility to sign a unit-linked life insurance with the following contract characteristics:

- Single premium at the signing of the contract: CHF 10,000

- Contract duration: 10 years

- Investment: the premiums will be invested in the financial markets either in a medium-risk fund $(50 \%$ stocks and $50 \%$ bonds) or in a high-risk fund $(100 \%$ stocks)

- Payout at maturity: worth of the fund's assets. Due to the uncertain development of the financial markets, the value of the fund and thus the payout are uncertain.

How high do you estimate the probability that the value of the fund's assets falls under CHF 10,000 at maturity, i. e. you become less than your deposited single premium? Please estimate a number between 0 percent (loss does not occur) and 100 percent (loss occurs in any case) by investment of the premium in a medium risk fund/high risk fund?

Figure 2. Design of the survey Part 2: Description of unit-linked product (I) and estimation of default probability.

guarantee and 2 per cent reservation price interest rate), giving them the guarantee prices obtained by option pricing theory (OPT). The guarantee prices are presented as absolute values payable at contract inception (at time $t=0$ ) to simplify the questionnaire as much as possible, and thus to ensure the participants' understanding of the setting. By positioning the choice question after asking for WTP, possible anchoring effects were avoided - as mentioned, participants could not change their answers to the judgement question after reading the choice questions with the calculated guarantee prices. Thus, this part sheds light on participants' decision behaviour, if the calculated guarantee prices, and hence cost transparency are given, since they are illustrated as total costs and not as monthly calculated payments or relative costs. Furthermore, the consistency of the answers of Part 2 can be checked.

\section{Empirical study: Descriptive statistics}

Fifteen outliers had to be removed from the 375 responses, leaving a total sample size of $360 .^{22}$ The information collected in Part 1 of the survey (customer characteristics) is presented in Table 2.

Table 2 shows that the majority of the participants are male (91 per cent), work in the field of insurance ( 84 per cent), have an education that includes knowledge of financial markets ( 84 per cent) and are aware that life insurance products typically contain investment guarantees (97 per cent). In addition, 84 per cent have stocks in their portfolio and thus have experience with the volatility of the financial market.

${ }^{22}$ The reasons for elimination were (a) obviously false statements concerning WTP, possibly due to a desire to move on to the next question in the survey (e.g., 123,456); (b) disproportionate overestimation of WTP, possibly due to the question being too complex for the participant (e.g., WTP twice as high as the initial premium invested in the fund); and (c) inconsistency in the given answers (e.g., participant with too small a WTP for a given guarantee chooses in the choice part a higher guarantee level). 


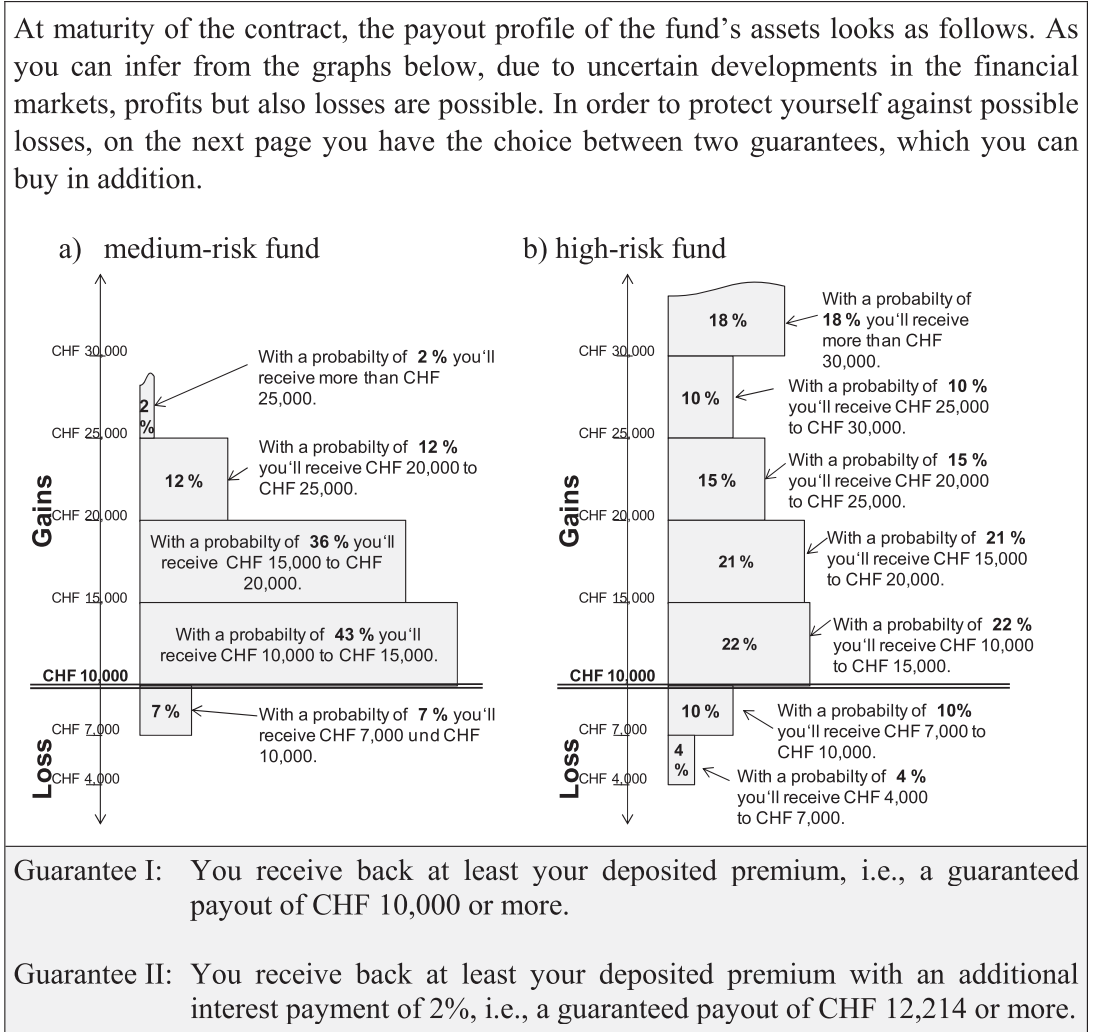

Figure 3. Design of the survey Part 2: Description of unit-linked product (II).

Most respondents are between 30-45 years old (52 per cent) and 46-65 years old (42 per cent). Interestingly, most respondents consider themselves risk-neutral (55 per cent), 27 per cent classify themselves as risk-seeking, while only 18 per cent are risk-averse. Even though all survey participants have some connection to insurance and finance, 19 per cent do not own a pension or life insurance product other than obligatory state pension schemes. Of those, 15 per cent do not even plan to buy insurance. However, most participants own at least one contract (81 per cent), of which more than half are unit-linked.

To summarise, while the majority of our respondents have experience with the stock market, have an educational and job profile related to insurance and finance and consider themselves risk-neutral or even risk-seeking, a substantial number are rather critical of life and pension products.

To analyse customer WTP for investment guarantees in unit-linked life insurance, we first examine descriptive statistics of WTP for different product designs and contrast them with prices based on OPT. Results are displayed in Table 3, including mean, median and standard deviation of results of Part 2 of the survey for unit-linked life policies with the two underlying funds and two levels of guarantee. In addition, we varied the amount of the initial premium to $\mathrm{CHF}$ 
How much is your maximal willingness to pay for a given guarantee, which you have to pay in addition to the single premium of CHF 10,000

(in $\mathrm{CHF}$ )

- with a medium-risk fund for Guarantee I (i.e., guaranteed payout of CHF 10,000 or more)?

- with a medium-risk fund for Guarantee II (i.e., guaranteed payout of CHF 12,214 or more)?

- with a high-risk fund for Guarantee I (i.e., guaranteed payout of CHF 10,000 or more)?

- with a high-risk fund for Guarantee II (i.e., guaranteed payout of CHF 12,214 or more)?

How much is your maximal willingness to pay for the given guarantee, when you now have to pay a single premium of CHF 50,000 (instead of CHF 10,000) and it is invested in a medium-risk fund

(in CHF)

- for Guarantee I (i.e., guaranteed payout of CHF 50,000 or more)?

- for Guarantee II (i.e., guaranteed payout of CHF 61,070 or more)?

How much is your maximal willingness to pay for the given guarantee, when your contract has a duration of 20 years (instead of 10 years) (single premium $=\mathrm{CHF}$ 10,000 ; medium-risk fund)

- for Guarantee I (i.e., guaranteed payout of CHF 10,000 or more)?

- for Guarantee II (i.e., guaranteed payout of CHF 14,918 or more)?

Figure 4. Design of the survey—Part 2: Willingness to pay.

50,000 (instead of CHF 10,000) and the contract term to 20 years (instead of ten years). The theoretical reservation price guarantee costs obtained using the BlackScholes formula in Eq. (2) are given in the first column of Table 3 ("OPT model"). The column "p-value" contains the results for the two-sided t-test on whether the average WTP ("mean") significantly differs from the insurer's reservation price calculated via option pricing.

The results in column 2 demonstrate that, on average, default probabilities were significantly overestimated. In the case of a medium-risk fund, for instance, the actual default probability given the input parameters of Table 1 is 7 per cent, while the subjective default probability estimated by the respondents is around 20 per cent. Despite this judgement, the respondents' WTP to prevent this default by purchasing an additional guarantee is significantly lower than the reservation price the insurer would be expected to charge given the input parameters. Taking Guarantee I and the underlying high-risk fund as an example, we find that the subjective WTP of CHF 401 is almost 65 per cent lower than the theoretically calculated guarantee cost of CHF 1,117. Similar results are observed for all product designs in Table 3 (second column), with the exception of Guarantee I for the longer contract term of 20 years, in which case the subjective price is almost equal to the OPT reservation price.

Table 3 also provides information on the WTP of the subsample that is willing to pay at least a positive amount (third column). The results show that between 10 and 
Here you have the choice among three products, which either do not contain a guarantee (Product A) or contain guarantees to different extents (Product B and Product C). Which of the three products would you choose in each case? Mark with a cross, please.

a) Your single premium is invested in the financial markets in a medium-risk fund (50\% stocks and $50 \%$ bonds).

$\square$ Product A: (1)

- No guarantee

- Payout of more or less than CHF 10,000 (depending on the evolution of financial markets)

- No additional costs

$\square$ Product B: (2)

- Guaranteed payout of the deposited single premium (i.e., CHF 10,000 or more, $0 \%$ yield)

- Additional costs for the guarantee: CHF 300

$\square$ Product C: (3)

- Premium returns a reservation price of $2 \%$ (guaranteed payout: CHF 12,214 or more)

- Additional costs for the guarantee: CHF 1,000

b) Your single premium is invested in the financial markets in a high-risk fund (100\% stocks).

$\square$ Product A: (1)

- No guarantee

- Payout of more or less than CHF 10,000 (depending on the evolution of financial markets)

- No additional costs

Product B: (2)

- Guaranteed payout of the deposited single premium (i.e., CHF 10,000 or more, $0 \%$ yield)

- Additional costs for the guarantee: CHF 1,120

Product C: (3)

- Premium returns a reservation price of $2 \%$ (guaranteed payout: $\mathrm{CHF}$ 12,214 or more)

- Additional costs for the guarantee: CHF 2,060

Figure 5. Design of the survey - Part 3: Choice of product.

Note: Italic numbers in parentheses display coding scheme.

37 per cent of the participants (depending on the product design) are not willing to pay a positive amount for an additional guarantee. Furthermore, in this subsample, WTP is no longer clear-cut. For instance, in the case of a medium-risk fund with Guarantee I, subjective WTP is almost the same as the theoretical price, but in the case 
Table 2 Survey part 1-Description of the sample (absolute frequency, percentage in parentheses)

\begin{tabular}{|c|c|}
\hline \multicolumn{2}{|l|}{ Gender } \\
\hline Male & $326(91 \%)$ \\
\hline Female & $34(9 \%)$ \\
\hline Total & $360(100 \%)$ \\
\hline \multicolumn{2}{|l|}{ Age (years) } \\
\hline $18-29$ & $19(5 \%)$ \\
\hline $30-45$ & $186(52 \%)$ \\
\hline $46-65$ & $152(42 \%)$ \\
\hline over 65 & $3(1 \%)$ \\
\hline Total & $360(100 \%)$ \\
\hline \multicolumn{2}{|l|}{$J o b$} \\
\hline I work in the area of insurance & $301(84 \%)$ \\
\hline I work in the area of financial services, but not in insurance & $27(7 \%)$ \\
\hline I work in a different area & $32(9 \%)$ \\
\hline Total & $360(100 \%)$ \\
\hline \multicolumn{2}{|l|}{ Education involves knowledge about financial markets } \\
\hline Yes & $302(84 \%)$ \\
\hline No & $58(16 \%)$ \\
\hline Total & $360(100 \%)$ \\
\hline \multicolumn{2}{|l|}{ Attitude towards risk } \\
\hline Risk averse & $65(18 \%)$ \\
\hline Risk neutral & $198(55 \%)$ \\
\hline Risk seeking & $97(27 \%)$ \\
\hline Total & $360(100 \%)$ \\
\hline \multicolumn{2}{|l|}{ Owning stocks? } \\
\hline Yes & $302(84 \%)$ \\
\hline No & $58(16 \%)$ \\
\hline Total & $360(100 \%)$ \\
\hline \multicolumn{2}{|l|}{ Know about investment guarantees in life insurance? } \\
\hline Yes & $348(97 \%)$ \\
\hline No & $12(3 \%)$ \\
\hline Total & $360(100 \%)$ \\
\hline \multicolumn{2}{|l|}{ Own a pension or life insurance product? } \\
\hline No, and signing a contract is not planned & $56(15 \%)$ \\
\hline No, but signing a contract is planned & $13(4 \%)$ \\
\hline Yes, I own one contract & $96(27 \%)$ \\
\hline Yes, I own multiple contracts & $195(54 \%)$ \\
\hline Total & $360(100 \%)$ \\
\hline \multicolumn{2}{|l|}{ If yes, is there a unit-linked product among them? } \\
\hline Yes, one & $99(28 \%)$ \\
\hline Yes, multiple & $48(13 \%)$ \\
\hline No & $143(40 \%)$ \\
\hline I don't know & $1(0 \%)$ \\
\hline Total & $291(81 \%)$ \\
\hline
\end{tabular}


Table 3 Survey part 2-Subjective WTP vs. guarantee costs $\Pi_{0}^{G}$ according to option pricing model OPT (in $\mathrm{CHF}$ )

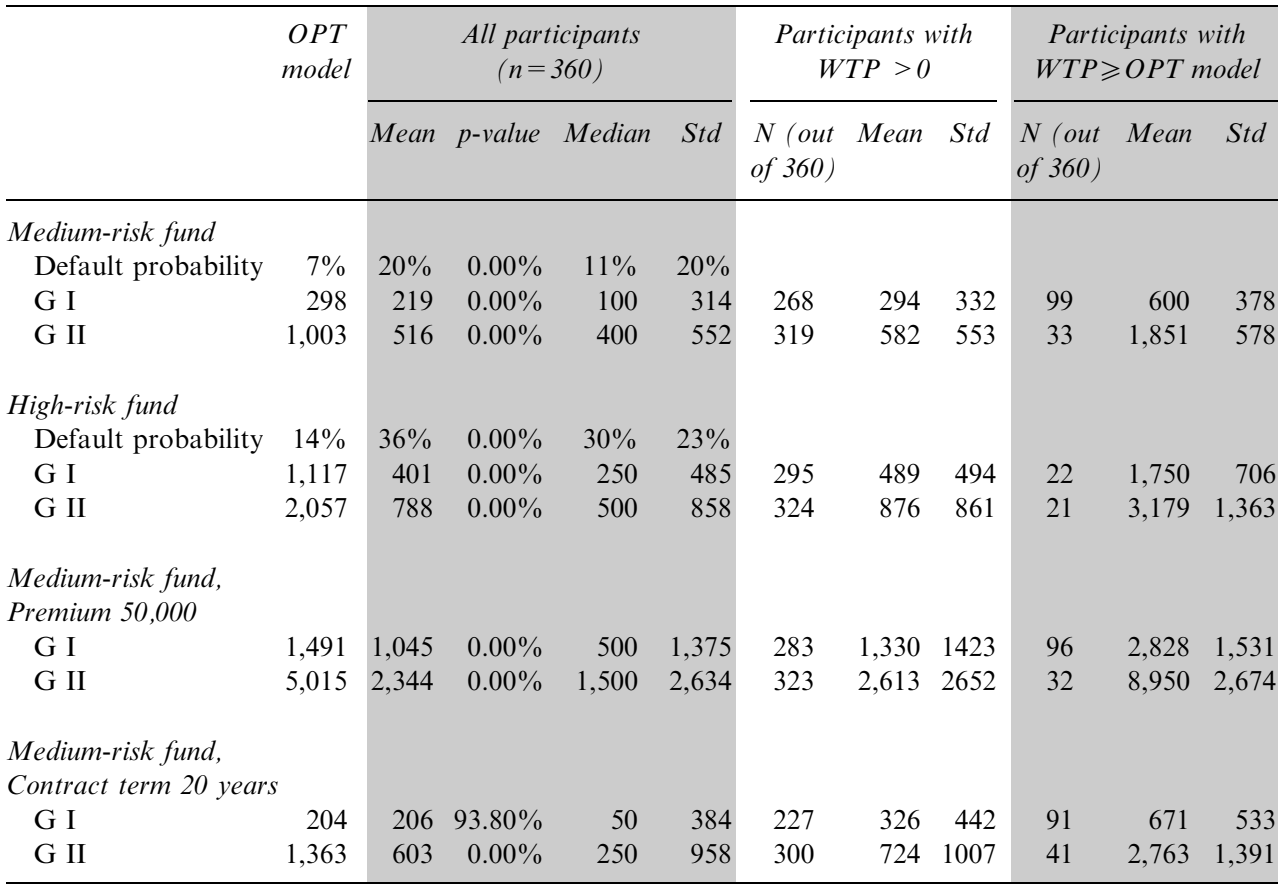

Notes: $\mathrm{G}$ I = money-back guarantee; $\mathrm{G}$ II $=2 \%$ guaranteed interest rate on premium; default probability $=$ probability that the maturity fund value falls below the single up-front premium; medium-risk fund $=50 \%$ bonds and $50 \%$ stocks; high-risk fund $=100 \%$ stocks; p-value for two-sided $t$-test (with respect to the guarantee costs according to option pricing theory (OPT) model with data from Table 1); $N=$ number of respondents with $\mathrm{WTP}>0$, respectively, with $\mathrm{WTP} \geqslant \mathrm{OPT}$.

of a contract term of 20 years, the WTP of CHF 326 on average significantly exceeds the price calculated using the OPT model (CHF 204). All other product designs, however, show a subjective WTP that is significantly less than the OPT model price.

Further analysis shows that WTP is significantly higher when the guarantee level is increased from I to II and when there is a switch from a medium- to a high-risk fund (using a one-sample $t$-test). Furthermore, we observe that in every case there are more people with a positive WTP for Guarantee II than there are for Guarantee I (i.e., fewer people are willing to pay anything for Guarantee I). Nevertheless, the WTP of those who are willing to pay for Guarantee I (except in the case of the highrisk fund) is always closer to the OPT model price than the WTP of those willing to pay for Guarantee II. The nature of the product also seems to have an impact on WTP. Most people with a positive WTP are found for the product investing in a high-risk fund and for the product with the medium-risk fund with an initial premium of CHF 50,000.

However, additional analysis reveals some people who are willing to pay more than the calculated reservation price, as illustrated in Table 3, right column. In the 
subsample with a positive WTP (Table 3, third column), more participants are willing to pay a positive price for Guarantee II than for Guarantee I. However, when looking at the subsample with a WTP exceeding the OPT price (Table 3, right column), we observe that for every product design, there are always more participants with a WTP that exceeds the insurer's OPT price for Guarantee I compared to Guarantee II. Thus, the price plays an important role in the decision-making process of buying (or not buying) additional guarantees, a finding that we will see again in Part 3 of the survey, where the participants have to choose among the different products for given OPT prices. Looking at the high standard deviations, we further find that for the subsample with a WTP higher than the OPT prices, stating the WTP will be difficult too. Furthermore, one has to question whether they are indeed willing to pay these prices in reality, especially those with an extraordinarily high WTP.

In order to analyse our findings, Table 4 provides the customer characteristics of the subsample with a WTP that exceeds the OPT price. The subsamples for every type of product design are similar to the main sample, but we can still observe certain shifts. In addition, comparing Table 4 with Table 2 shows that the number of risk-averse people willing to pay more than the OPT price increased (e.g., for products with a higher initial premium). Whereas most participants of the main sample own at least one unit-linked product, the majority of all subsamples possess no unit-linked life insurance product.

To obtain a more comprehensive picture of customer preferences, Part 3 of the survey asked participants to choose among three unit-linked products, given OPT guarantee prices (see also the first column, "OPT model", of Table 3). Results are displayed in Table 5. Consistent with the results from Table 3, we find that a majority of the participants chose Product A without any additional guarantee (44 per cent medium-risk fund/44 per cent high-risk fund). However, a substantial proportionmore than half-remains willing to purchase an additional guarantee. Overall, more participants prefer the money-back guarantee to the 2 per cent interest rate guarantee. The results are similar when comparing the results for the underlying medium- and the high-risk fund. However, while Table 3 shows that demand is, generally speaking, higher for Guarantee II than for Guarantee I, we see from Table 5 that many respondents prefer a product without any additional guarantees when they are confronted with the OPT model-based prices. As all participants were consistent with their previous statements concerning WTP (no one chose a product in Part 3 that exceeded his or her WTP), we may assume that it is not the idea of a guarantee per se that discourages customers from buying one, but the price - even though the OPT price for the guarantee in our model is generally lower than it would be in reality.

In summary, this descriptive analysis demonstrates the difficulty in assessing the value of an investment guarantee in a unit-linked life insurance policy. By comparing subjective guarantee values with reservation prices obtained using a theoretical option pricing model, we show that respondents, even though they all had a background in financial services with experience in financial markets, valued guarantees were significantly lower than the theoretical price. Thus, even though a direct judgement of the value of a guarantee is highly complex and difficult for the participants - even in this fairly knowledgeable sample-the empirical findings still allow the tentative conclusion that the true value of investment guarantees may not be fully acknowledged by customers. However, when providing the theoretical prices and then asking 


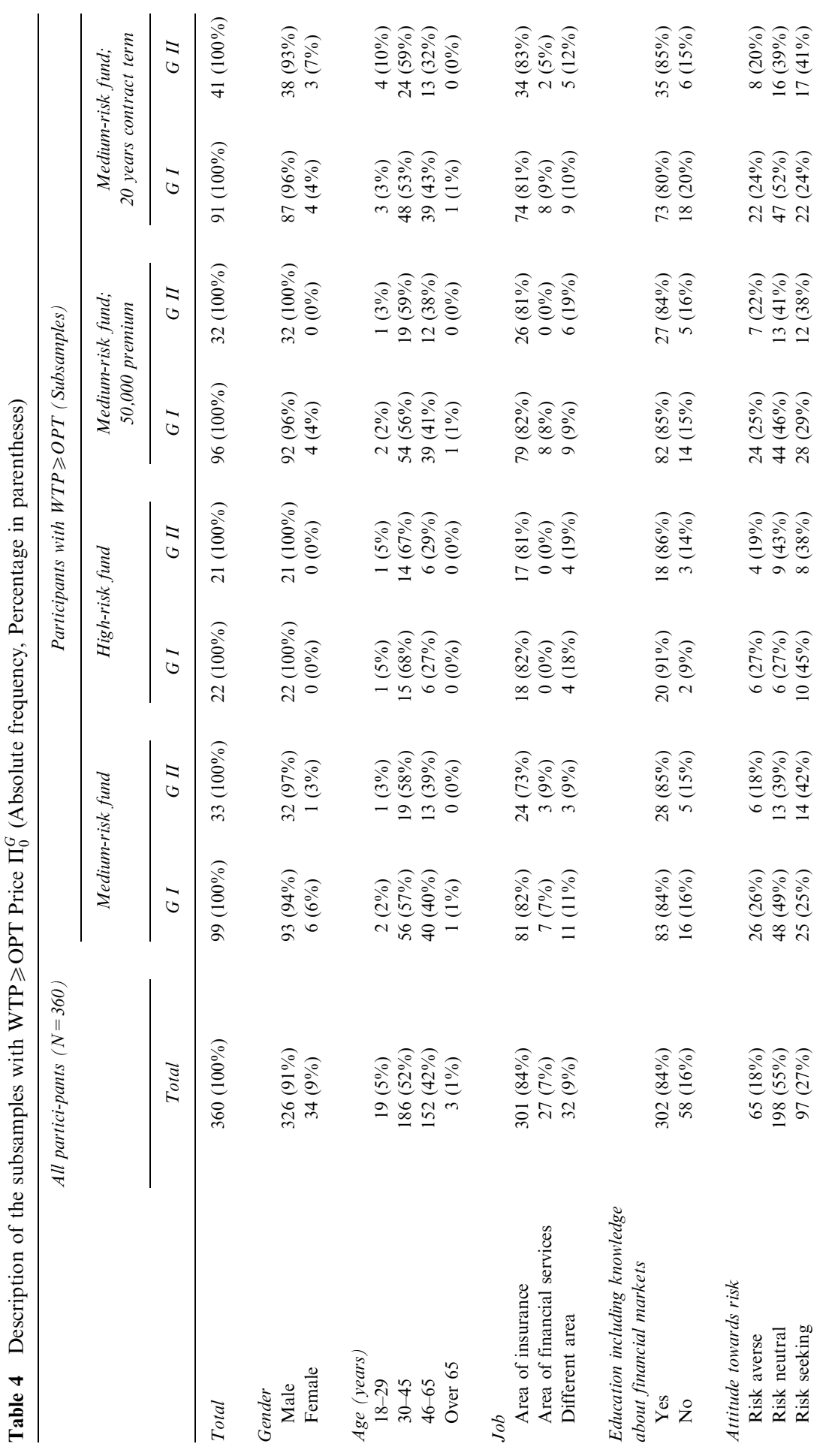




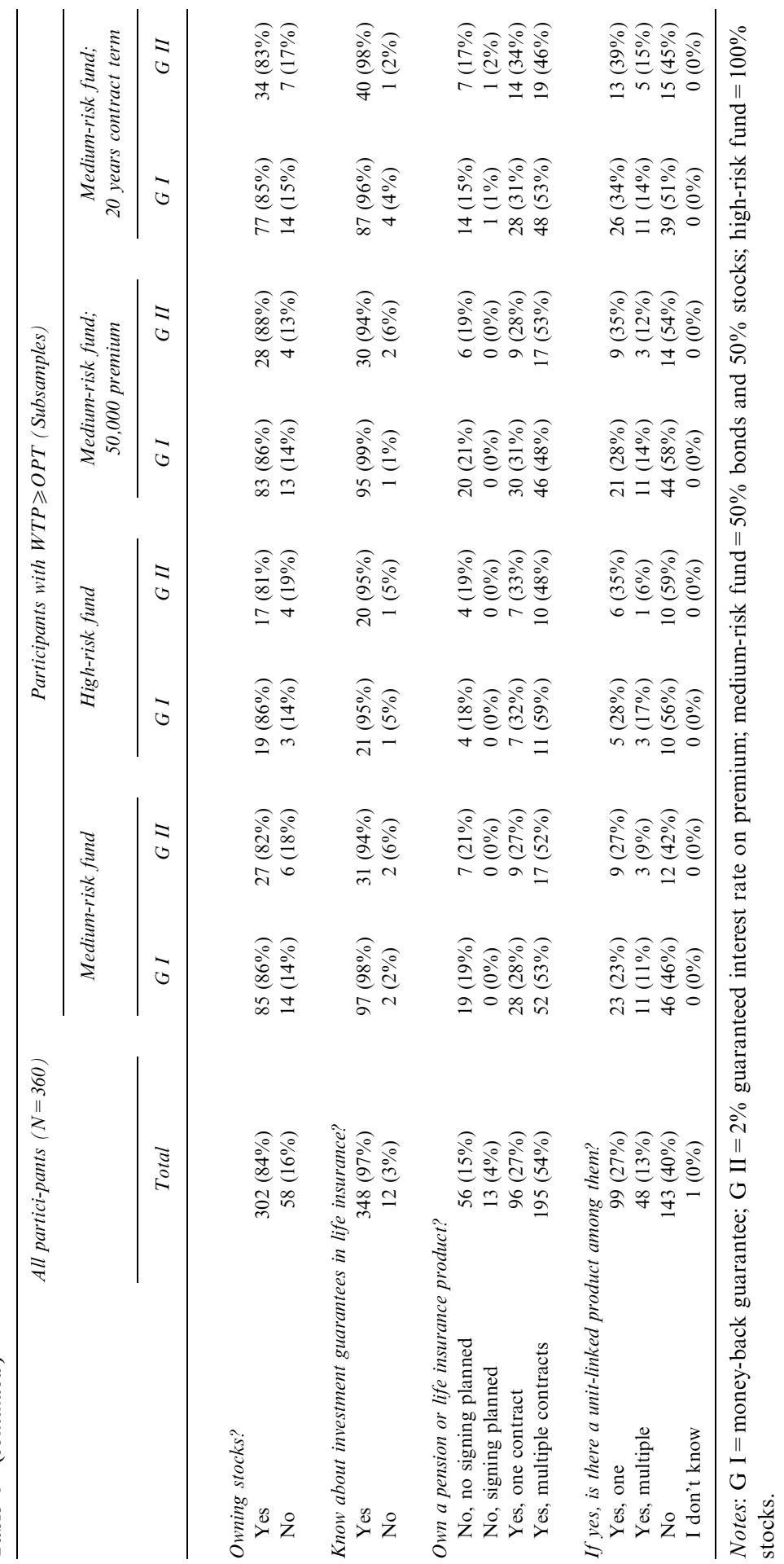


Table 5 Survey part 3 - Choice among three unit-linked life insurance products given option pricing model OPT prices $\Pi_{0}^{G}$; (Absolute frequency, percentage in parentheses)

\begin{tabular}{lccc}
\hline & $\begin{array}{c}\text { Product A: } \\
\text { no guarantee } \\
\text { no additional costs }\end{array}$ & $\begin{array}{c}\text { Product B: } \\
\text { money-back guarantee } \\
\text { CHF 300 (for medium risk) } \\
\text { CHF 1,000 (for high risk) }\end{array}$ & $\begin{array}{c}\text { Product C: } \\
\text { 2\% reservation price } \\
\text { interest rate guarantee } \\
\text { CHF 1,120 (for medium risk) } \\
\text { CHF 2,060 (for high risk) }\end{array}$ \\
\hline $\begin{array}{l}\text { Medium-risk fund } \\
\text { High-risk fund }\end{array}$ & $157(44 \%)$ & $124(34 \%)$ & $79(22 \%)$ \\
\hline
\end{tabular}

participants to choose among unit-linked products with different guarantee levels for the given price, a large number of them would still select a guarantee, even though more than 40 per cent consistently chose the product without an additional guarantee. The results of the choice option are certainly influenced by the presentation of the OPT prices (see Figure 5). Giving the participants' absolute values of the costs and the premium, and thus the demanded transparency and cost overview, probably leads to a different WTP than giving, for example, monthly calculated payments (small vs. big numbers) or relative costs (under-/overestimation of probabilities).

\section{Empirical study: Further analysis of relationships}

To provide further insight into the relationship between customer characteristics and WTP, Tables 6 and 7 display the respective correlations (see Figure 1 for coding). Aside from some insight into the estimation, customer characteristics appear to play only a minor role in assessing subjective WTP and estimating default probabilities. However, we do find that women have a lower WTP for guarantees, which is found to be significant for Guarantee I of the medium-risk fund and Guarantee II of the high-risk fund.

Older people are willing to pay more (except for Guarantee II medium risk) and have a higher subjective estimate of default probabilities. A significant relation of this is found for the default probability of the high-risk fund. Other characteristics with significant relation were persons having a job in an area other than insurance or finance, who tend to more greatly underestimate the default probability for the high-risk fund compared to persons working in insurance or financial services. At the same time, these people have a higher WTP for investment guarantees (except for Guarantee I high-risk fund).

Persons without an education in financial markets estimate the default probability as significantly higher than do persons who do have such an education. Participants owning one or more life or pension products are willing to pay less than those without life insurance products, even though their subjective default probability for the high-risk fund is slightly higher. Persons with more than one life or pension product have a lower WTP for both types of guarantees and both fund types. Similar results are observed for the fund with an initial premium of CHF 50,000, for the fund with a contract term of 20 years, and for the choice options.

These findings are confirmed by an ANOVA analysis between customer characteristics and WTP, as shown in Table 8 . The table reveals that customer 
Table 6 Correlations between customer characteristics and WTP

\begin{tabular}{|c|c|c|c|c|c|c|}
\hline & \multicolumn{3}{|c|}{ Medium-risk fund } & \multicolumn{3}{|c|}{ High-risk fund } \\
\hline & Default probability & $G I$ & $G I I$ & Default probability & $G I$ & $G I I$ \\
\hline \multicolumn{7}{|l|}{ Gender } \\
\hline Pearson correlation & -0.038 & -0.093 & -0.058 & 0.044 & -0.063 & -0.088 \\
\hline Sig. (2-tailed) & 0.471 & 0.079 & 0.274 & 0.405 & 0.231 & 0.097 \\
\hline \multicolumn{7}{|l|}{ Age } \\
\hline Pearson correlation & 0.079 & 0.048 & -0.030 & $0.136 * *$ & 0.049 & 0.021 \\
\hline Sig. (2-tailed) & 0.132 & 0.360 & 0.568 & 0.010 & 0.354 & 0.687 \\
\hline \multicolumn{7}{|l|}{ Job } \\
\hline Pearson correlation & -0.067 & 0.058 & 0.066 & $-0.105^{*}$ & -0.005 & 0.005 \\
\hline Sig. (2-tailed) & 0.207 & 0.270 & 0.213 & 0.047 & 0.919 & 0.930 \\
\hline \multicolumn{7}{|l|}{ Education } \\
\hline Pearson correlation & 0.101 & -0.005 & -0.004 & $0.112^{*}$ & 0.018 & 0.023 \\
\hline Sig. (2-tailed) & 0.055 & 0.928 & 0.943 & 0.034 & 0.728 & 0.665 \\
\hline \multicolumn{7}{|l|}{ Attitude towards risk } \\
\hline Pearson correlation & 0.035 & -0.050 & -0.010 & 0.008 & -0.081 & -0.021 \\
\hline Sig. (2-tailed) & 0.503 & 0.340 & 0.850 & 0.875 & 0.126 & 0.692 \\
\hline \multicolumn{7}{|l|}{ Owning stocks? } \\
\hline Pearson Correlation & -0.095 & -0.013 & 0.048 & -0.049 & 0.025 & 0.031 \\
\hline Sig. (2-tailed) & 0.072 & 0.812 & 0.364 & 0.358 & 0.630 & 0.560 \\
\hline \multicolumn{7}{|c|}{ Knowledge about guarantees } \\
\hline Pearson correlation & 0.031 & -0.043 & -0.008 & -0.013 & -0.056 & -0.033 \\
\hline Sig. (2-tailed) & 0.562 & 0.413 & 0.880 & 0.810 & 0.287 & 0.536 \\
\hline \multicolumn{7}{|c|}{ Owning a life insurance product } \\
\hline Pearson correlation & 0.053 & -0.017 & -0.030 & $0.122 *$ & -0.013 & -0.052 \\
\hline Sig. (2-tailed) & 0.311 & 0.754 & 0.569 & 0.021 & 0.813 & 0.324 \\
\hline
\end{tabular}

* Correlation is significant at the 0.05 level (2-tailed); ** Correlation is significant at the 0.01 level (2-tailed). Notes: G I = money-back guarantee; G II = 2\% guaranteed interest rate on premium; default probability $=$ probability that the maturity fund value falls below the single up-front premium; medium-risk fund $=50 \%$ bonds and $50 \%$ stocks; high-risk fund $=100 \%$ stocks.

characteristics have no significant effect on levels of WTP, except of the characteristic "gender", and neither do they reveal a significant trend. Only "gender" shows significant differences in respect to the WTP of men and women. For all types of guarantees, we observe that men are willing to pay considerably more than women. This proves significant for Guarantee I and II for the medium risk fund with an initial up-front premium of CHF 50,000, both on a 0.05 level. In these two cases, women are on average willing to pay more than 50 per cent less than men. However, the average WTP of men is still too small to cover the reservation price calculated using OPT. Except for the customer characteristic "gender", customer characteristics do not show any significant differences between groups, and thus do 
Table 7 Correlations between customer characteristics and WTP

\begin{tabular}{|c|c|c|c|c|c|c|}
\hline & \multicolumn{2}{|c|}{$\begin{array}{l}\text { Medium-risk fund, Premium } \\
50,000\end{array}$} & \multicolumn{2}{|c|}{$\begin{array}{c}\text { High-risk fund, Contract } \\
\text { term } 20 \text { years }\end{array}$} & \multicolumn{2}{|c|}{$\begin{array}{l}\text { Product choice } \\
\text { (product } A-C \text { ) }\end{array}$} \\
\hline & $G I$ & $G I I$ & $G I$ & $G I I$ & $M R F$ & $H R F$ \\
\hline \multicolumn{7}{|l|}{ Gender } \\
\hline Pearson correlation & $-0.107^{*}$ & $-0.117^{*}$ & -0.020 & -0.005 & -0.056 & 0.015 \\
\hline Sig. (2-tailed) & 0.042 & 0.027 & 0.705 & 0.916 & 0.286 & 0.773 \\
\hline \multicolumn{7}{|l|}{ Age } \\
\hline Pearson correlation & 0.031 & -0.034 & 0.005 & -0.054 & 0.066 & 0.051 \\
\hline Sig. (2-tailed) & 0.561 & 0.520 & 0.921 & 0.306 & 0.211 & 0.335 \\
\hline \multicolumn{7}{|l|}{$J o b$} \\
\hline Pearson correlation & 0.033 & 0.051 & 0.018 & 0.023 & 0.069 & 0.008 \\
\hline Sig. (2-tailed) & 0.528 & 0.331 & 0.727 & 0.665 & 0.192 & 0.873 \\
\hline \multicolumn{7}{|l|}{ Education } \\
\hline Pearson correlation & -0.021 & -0.015 & -0.015 & 0.005 & 0.093 & 0.051 \\
\hline Sig. (2-tailed) & 0.688 & 0.780 & 0.778 & 0.919 & 0.079 & 0.330 \\
\hline \multicolumn{7}{|l|}{ Attitude towards risk } \\
\hline Pearson correlation & -0.049 & -0.024 & -0.079 & 0.018 & -0.011 & -0.053 \\
\hline Sig. (2-tailed) & 0.355 & 0.648 & 0.136 & 0.731 & 0.834 & 0.312 \\
\hline \multicolumn{7}{|l|}{ Owning stocks? } \\
\hline Pearson correlation & -0.025 & -0.002 & -0.055 & 0.059 & 0.064 & 0.032 \\
\hline Sig. (2-tailed) & 0.638 & 0.975 & 0.298 & 0.263 & 0.229 & 0.540 \\
\hline \multicolumn{7}{|c|}{ Knowledge about guarantees } \\
\hline Pearson correlation & -0.039 & -0.001 & -0.037 & 0.010 & -0.067 & -0.067 \\
\hline Sig. (2-tailed) & 0.456 & 0.982 & 0.487 & 0.845 & 0.202 & 0.205 \\
\hline \multicolumn{7}{|c|}{ Owning a life insurance product } \\
\hline Pearson correlation & -0.027 & -0.035 & 0.015 & -0.017 & -0.069 & -0.072 \\
\hline Sig. (2-tailed) & 0.607 & 0.505 & 0.771 & 0.741 & 0.193 & 0.176 \\
\hline
\end{tabular}

*Correlation is significant at the 0.05 level (2-tailed).

Notes: $\mathrm{G} \mathrm{I}=$ money-back guarantee; $\mathrm{G} \mathrm{II}=2 \%$ guaranteed interest rate on premium; default probability $=$ probability that the maturity fund value falls below the single up-front premium; medium-risk fund $=50 \%$ bonds and $50 \%$ stocks; high-risk fund $=100 \%$ stocks.

not represent good predictors of WTP by group. These results indicate that even within different groups, it is difficult to state WTP.

\section{Discussion and policy implications}

The results of our empirical study show that participants are on average not willing to pay the reservation price necessary to secure the guarantees in insurance products. This is true, even though the cost of the guarantee in our model can in general be considered to represent a lower bound to the "true costs" due to the underlying assumptions (no inclusion of, for example, jumps in the underlying asset process, stochastic volatility, transaction costs). Thus, the market price might even be higher. Nevertheless, we found 
Table 8 ANOVA between customer characteristics and WTP

\begin{tabular}{|c|c|c|c|c|c|c|c|c|}
\hline \multirow[t]{3}{*}{ OPT model (in CHF) } & \multicolumn{2}{|c|}{ Medium-risk fund } & \multicolumn{2}{|c|}{ High-risk fund } & \multicolumn{2}{|c|}{$\begin{array}{l}\text { Medium-risk fund, } \\
\text { 50,000 premium }\end{array}$} & \multicolumn{2}{|c|}{$\begin{array}{c}\text { Medium-risk fund } \\
20 \text { years } \\
\text { contract term }\end{array}$} \\
\hline & $G I$ & $G I I$ & $G I$ & $G I I$ & $G I$ & $G I I$ & $G I$ & $G I I$ \\
\hline & 298 & 1003 & 1116 & 2057 & 1491 & 5015 & 204 & 1363 \\
\hline \multicolumn{9}{|l|}{ Gender } \\
\hline Mean total (in CHF) & 219 & 516 & 401 & 788 & 1,045 & 2,344 & 206 & 603 \\
\hline Male & 228 & 526 & 411 & 813 & 1,093 & 2,444 & 208 & 605 \\
\hline Female & 129 & 417 & 306 & 556 & 590 & 1,393 & 182 & 588 \\
\hline$F$ & 3.100 & 1.200 & 1.438 & 2.774 & 4.148 & 4.951 & 0.143 & 0.010 \\
\hline Sig. & 0.079 & 0.274 & 0.231 & 0.097 & $0.042^{*}$ & $0.027 *$ & 0.705 & 0.919 \\
\hline \multicolumn{9}{|l|}{ Age } \\
\hline Mean total (in $\mathrm{CHF}$ ) & 219 & 516 & 401 & 788 & 1,045 & 2,344 & 206 & 603 \\
\hline $18-29$ years & 106 & 480 & 225 & 663 & 530 & 1,924 & 87 & 775 \\
\hline $30-45$ years & 223 & 539 & 405 & 786 & 1094 & 2,516 & 227 & 624 \\
\hline $46-65$ years & 230 & 498 & 422 & 817 & 1058 & 2,210 & 195 & 562 \\
\hline Over 65 years & 133 & 267 & 167 & 333 & 600 & 1,200 & 167 & 333 \\
\hline$F$ & 0.963 & 0.389 & 1.170 & 0.471 & 1.079 & 0.742 & 0.844 & 0.404 \\
\hline Sig. & 0.410 & 0.761 & 0.321 & 0.703 & 0.358 & 0.527 & 0.471 & 0.750 \\
\hline \multicolumn{9}{|l|}{ Job } \\
\hline Mean total (in CHF) & 219 & 516 & 401 & 788 & 1,045 & 2,344 & 206 & 603 \\
\hline Insurance area & 213 & 508 & 408 & 800 & 1,033 & 2,325 & 199 & 598 \\
\hline Financial area & 206 & 387 & 263 & 507 & 956 & 1,674 & 305 & 549 \\
\hline Different area & 286 & 694 & 450 & 921 & 1,239 & 3,088 & 188 & 701 \\
\hline$F$ & 0.814 & 2.438 & 1.285 & 1.866 & 0.386 & 2.169 & 0.995 & 0.213 \\
\hline Sig. & 0.444 & 0.089 & 0.278 & 0.156 & 0.68 & 0.116 & 0.371 & 0.809 \\
\hline \multicolumn{9}{|c|}{ Education involving knowledge about financial markets } \\
\hline Mean total (in CHF) & 219 & 516 & 401 & 788 & 1,045 & 2,344 & 206 & 603 \\
\hline Yes & 220 & 517 & 397 & 780 & 1,058 & 2,361 & 208 & 601 \\
\hline No & 215 & 511 & 421 & 833 & 979 & 2,256 & 193 & 615 \\
\hline$F$ & 0.008 & 0.005 & 0.121 & 0.187 & 0.161 & 0.078 & 0.080 & 0.010 \\
\hline Sig. & 0.928 & 0.943 & 0.728 & 0.665 & 0.688 & 0.780 & 0.778 & 0.919 \\
\hline \multicolumn{9}{|l|}{ Attitude towards risk } \\
\hline Mean total (in $\mathrm{CHF}$ ) & 219 & 516 & 401 & 788 & 1,045 & 2,344 & 206 & 603 \\
\hline Risk averse & 266 & 559 & 505 & 890 & 1,280 & 2,726 & 278 & 617 \\
\hline Risk neutral & 207 & 494 & 380 & 743 & 972 & 2,171 & 194 & 573 \\
\hline Risk loving & 211 & 531 & 374 & 813 & 1,037 & 2,443 & 180 & 655 \\
\hline$F$ & 0.895 & 0.395 & 1.836 & 0.773 & 1.231 & 1.179 & 1.471 & 0.245 \\
\hline Sig. & 0.410 & 0.674 & 0.161 & 0.463 & 0.293 & 0.309 & 0.231 & 0.782 \\
\hline \multicolumn{9}{|l|}{ Owning stocks? } \\
\hline Mean total (in CHF) & 219 & 516 & 401 & 788 & 1,045 & 2,344 & 206 & 603 \\
\hline Yes & 221 & 504 & 395 & 777 & 1,060 & 2,346 & 215 & 579 \\
\hline No & 210 & 576 & 429 & 849 & 967 & 2,334 & 157 & 733 \\
\hline$F$ & 0.057 & 0.826 & 0.233 & 0.340 & 0.222 & 0.001 & 1.087 & 1.258 \\
\hline Sig. & 0.812 & 0.364 & 0.630 & 0.560 & 0.638 & 0.975 & 0.298 & 0.263 \\
\hline
\end{tabular}


Table 8 (continued)

\begin{tabular}{|c|c|c|c|c|c|c|c|c|}
\hline \multirow[t]{3}{*}{ OPT model (in $\mathrm{CHF}$ ) } & \multicolumn{2}{|c|}{ Medium-risk fund } & \multicolumn{2}{|c|}{ High-risk fund } & \multicolumn{2}{|c|}{$\begin{array}{c}\text { Medium-risk fund, } \\
\text { 50,000 premium }\end{array}$} & \multicolumn{2}{|c|}{$\begin{array}{c}\text { Medium-risk fund, } \\
20 \text { years } \\
\text { contract term }\end{array}$} \\
\hline & $G I$ & $G I I$ & $G I$ & $G I I$ & $G I$ & $G I I$ & $G I$ & $G I I$ \\
\hline & 298 & 1003 & 1116 & 2057 & 1491 & 5015 & 204 & 1363 \\
\hline \multicolumn{9}{|l|}{ Knowledge about guarantees } \\
\hline Mean total (in CHF) & 219 & 516 & 401 & 788 & 1,045 & 2,344 & 206 & 603 \\
\hline Yes & 221 & 517 & 406 & 794 & 1,055 & 2,345 & 208 & 602 \\
\hline No & 146 & 492 & 254 & 638 & 754 & 2,328 & 130 & 657 \\
\hline$F$ & 0.671 & 0.023 & 1.139 & 0.383 & 0.556 & 0.001 & 0.483 & 0.038 \\
\hline Sig. & 0.413 & 0.880 & 0.287 & 0.536 & 0.456 & 0.982 & 0.487 & 0.845 \\
\hline \multicolumn{9}{|l|}{ Owning a life insurance product } \\
\hline Mean total (in CHF) & 219 & 516 & 401 & 788 & 1,045 & 2,344 & 206 & 603 \\
\hline No (no signing planned) & 246 & 552 & 427 & 904 & 1,204 & 2,607 & 218 & 618 \\
\hline No (signing planned) & 54 & 396 & 232 & 607 & 367 & 1,616 & 29 & 662 \\
\hline Yes (one contract) & 238 & 551 & 425 & 816 & 1,103 & 2,457 & 209 & 630 \\
\hline Yes (multiple contracts) & 213 & 496 & 393 & 754 & 1,017 & 2,262 & 212 & 582 \\
\hline$F$ & 1.478 & 0.501 & 0.675 & 0.669 & 1.391 & 0.637 & 0.956 & 0.076 \\
\hline Sig. & 0.220 & 0.682 & 0.568 & 0.572 & 0.245 & 0.592 & 0.414 & 0.973 \\
\hline
\end{tabular}

* $F$ is significant at the 0.05 level.

Notes: $\mathrm{G} \mathrm{I}=$ money-back guarantee; $\mathrm{G} \mathrm{II}=2 \%$ guaranteed interest rate on premium; medium-risk fund $=50 \%$ bonds and $50 \%$ stocks; high-risk fund $=100 \%$ stocks.

that people are generally positively disposed towards guarantees, especially in the case of high-risk products or products with a higher premium volume. Moreover, for every type of guarantee, we still find a substantial portion of up to one-third of the participants who are willing to pay a price that substantially exceeds the reservation price. Further research could thus focus on the characteristics of this group in more detail and analyse biases as to what extent the hypothetical WTP may or may not be overestimated. In addition, it would be worthwhile to compare the results for WTP in a different time period when historical volatility and thus guarantee costs are lower. However, at the moment, customers' average maximum WTP in our sample does not cover the reservation price derived by OPT.

Furthermore, people find it difficult to directly assess "true" subjective WTP for insurance-related guarantees, even though the sample is specialised in finance or insurance. This finding was confirmed when considering the substantial deviations of the stated WTP and the high number of outliers, which makes a direct assessment of "true" subjective prices for guarantees very difficult. There are several explanations for this finding. First, perhaps the most obvious reason is the complexity of the product. Specifically, even for our fairly knowledgeable sample, the products are complicated for consumers to evaluate in anything close to an objective manner. Second, most consumers have only a very low involvement with insurance products and very rarely engage in making insurance purchase decisions. Third, we conducted a survey that included direct open-response questions eliciting subjective WTP, a cognitively very 
demanding task. The high deviations of stated WTP may indicate an absence of a reference price. A reference price is an anchor or benchmark against which the product price is judged. ${ }^{1,23}$ Interestingly, even the sample with insurance or finance background seems to be unable to rely on such a standard. Thus, it might be even more difficult for typical customers to assess their WTP for investment guarantees. However, in this analysis the discussion of the existence of a reference price can only be a tentative derivation, and has to be confirmed in further research. ${ }^{24}$ Even so, by directly asking whether and how much people are willing to pay for guarantees, the survey should be a first step in determining how well these products are understood, and to what extent subjective WTP differs from insurers' OPT prices.

Interestingly, customer characteristics, such as age, gender or risk attitude, had no influence on these findings, as reflected in the lack of statistical significance. It thus appears that even for our sample, more than 90 per cent of whom work in insurance or finance, customer characteristics have only very low power in explaining WTP, customer estimates of default probabilities and the general lack of understanding the products. This is true even for our sample, where more than 90 per cent of participants work in the fields of insurance or finance.

Due to the non-representative selection of the sample and the not entirely given validity and reliability in the direct approach, our findings and their implications cannot be generalised. However, even though interpretations and policy implications are tentative, the present research still allows for deduction of some practical implications for insurers.

First, and as pointed out earlier, insurance products are very complex, and people may not be able to fully understand these products or single elements of them, much less evaluate or compare them entirely. Consequently, the question arises as to whether it is advisable and justifiable to offer rather complex products instead of a transparent product design that may increase customer value. Second, on average, the WTP for investment guarantees does not cover the reservation price. Thus, the question arises as to what extent the product design considers customer preferences and, more specifically, the trade-off between the wish for high guarantees (and thus a secure payoff at maturity) and the associated costs. Certainly, life insurance products with different types of embedded guarantees may imply a unique selling proposition for insurance companies. However, the results of the study challenge the reasonability of investment guarantees in this context, especially in regard to the insufficient average WTP, if costs are communicated in a transparent way. This is important in the context of the current demand for more transparency, since our empirical study suggests that customers may often not choose the products or pay the required price when they are fully informed about absolute costs and payoff structure. However, these results may change when altering, for example, the presentation of the premium payment method (e.g., monthly instead of up-front; percentage of fund value instead of absolute). Third, regulatory authorities and tax subsidies generally obligate people to buy guarantees, even if customers may not be willing to voluntarily buy and pay for

\footnotetext{
${ }^{23}$ Mazumdar et al., 2005; Monroe, 1973.

${ }^{24}$ See, for example, Lowe and Alpert, 2007.
} 
these guarantees. Thus, regulatory authorities should reflect requirements in regard to guarantees against the background of customers' interests. Doubtless, it is important to protect customers, and in particular to prevent poverty among the elderly, but at the same time, massive regulatory frameworks may constrict market mechanisms and thus conceal cost transparency.

Hence, to summarise these tentative implications, it is worthwhile to consider whether insurance companies should reassess their product designs and to conduct an in-depth analysis of customer needs in order to ensure a sufficient WTP that exceeds the reservation price. Further, regulatory authorities should readjust their frameworks. Both, regulatory authorities and insurance companies, should focus on a reduction of complexity, an increase of (cost) transparency, and a more comprehensive consideration of customer preferences, e.g., by integration of customer surveys. However, due to the specific choice of the sample and the method, these implications can only be considered as a first indication, and have to be confirmed in further research.

\section{Summary and outlook}

In this paper, prices for investment guarantees for unit-linked life or pension products based on options pricing theory were compared to subjective WTP. To elicit the subjective WTP, we administered an online questionnaire comprising direct open-response questions and choice options. The results were compared to the actual reservation price calculated with the Black and Scholes option pricing formula. The majority of the participants had some connection to either insurance or finance, an aspect of survey design necessitated by the complexity of the products they were asked to evaluate and choose from and the subject matter of the direct open-response questions.

The results of this study show that the average WTP of customers for investment guarantees in unit-linked life insurance products is significantly lower than the reservation price the insurer would be expected to charge. However, there was still a substantial portion of participants whose WTP considerably exceeded the insurer's reservation price. Customer characteristics had almost no influence on the WTP, and differences between groups could hardly be observed. Our results indicate first implications, such as the reassessing of product designs by insurers, and of the regulatory framework by regulatory authorities, which have to be analysed in detail in further analyses.

We have shown that on average, there is too little WTP for guarantees in unit-linked life insurance, and not much of a link, if any, between customer characteristics and WTP. Thus, the way is now cleared for work on determining indirect WTP and why subjective prices are so low on average and still high for a considerable portion of the sample. Thus, the data from this study constitute a first step in examining the contrast between reservation prices for guarantees in unit-linked life insurance policies based on a financial pricing approach and the subjective WTP of customers. However, it is difficult to examine the "real" willingness of consumers, especially since insurance products are perceived as product bundles, comprised of several items, including price, service and image. Thus, there is a discrepancy between real and hypothetical WTP. The next step is to replicate and extend this study by investigating these dimensions for buying insurance, 
measuring their extent and analysing indirect WTP for guarantees by conducting a conjoint analysis on a panel representing, for example, the Swiss population.

\section{Acknowledgements}

The authors would like to thank two anonymous referees as well as the participants of the 2009 Annual Meeting of the American Risk and Insurance Association and the 2010 Annual Meeting of Deutscher Verein für Versicherungswirtschaft for valuable suggestions and comments on an earlier draft of this paper. The authors gratefully acknowledge financial support by the Swiss National Science Foundation.

\section{References}

Albrecht, P. and Maurer, R. (2000) 'Zur bedeutung der ausfallbedrohtheit von Versicherungskontrakten — ein Beitrag zur behavioral insurance', Zeitschrift für die gesamte Versicherungswissenschaft 89(2/3): 339-355.

Björk, T. (2004) Arbitrage Theory in Continuous Time, New York: Oxford University Press.

Breidert, C., Hahsler, M. and Reutterer, T. (2006) 'A review of methods for measuring willingness-to-pay', Innovative Marketing 2(4): 8-32.

Diller, H. (2000) Preispolitik, Stuttgart: Kohlhammer.

Gatzert, N. and Schmeiser, H. (2009) 'Pricing and performance of mutual funds: Lookback versus interest rate guarantees', Journal of Risk 11(4): 887-908.

Gatzert, N., Holzmueller, I. and Schmeiser, H. (2009) Creating customer value in participating life insurance, Working Paper on Risk Management and Insurance, University of St. Gallen.

Harrison, J. and Kreps, D. (1979) 'Martingales and arbitrage in multiperiod securities markets', Journal of Economic Theory 20: 381-408.

Hull, J. (2008) Options, Futures, and Other Derivatives, $7^{\text {th }}$ edn, New Jersey: Pearson.

Johnson, E., Hershey, J., Meszaros, J. and Kunreuther, H. (1993) 'Framing, probability distortions, and insurance decisions', Journal of Risk and Uncertainty 7(1): 35-51.

Kahneman, D. and Tversky, A. (1979) 'Prospect theory: An analysis of decision under risk', Econometrica 47(2): 263-291.

Kahneman, D. and Tversky, A. (1984) 'Choices, values, and frames', American Psychologist 39(4): 341-350.

Lachance, M-E. and Mitchell, O.S. (2003) 'Understanding individual account guarantees', American Economic Review 93(2): 257-260.

Loewenstein, G.F. and Prelec, D. (1992) 'Anomalies in intertemporal choice: Evidence and an interpretation', Quarterly Journal of Economics 107(2): 573-597.

Lowe, B. and Alpert, F. (2007) 'Measuring reference price perceptions for new product categories: Which measure is best?' Journal of Product and Brand Management 16(2): 132-141.

Mazumdar, T., Raj, S.P. and Sinha, I. (2005) 'Reference price research: Review and propositions', Journal of Marketing 69(4): 84-102.

Miller, K., Hofstetter, R., Krohmer, H. and Zhang, J. (2010) 'How should we measure consumers willingness to pay? An empirical comparison of state-of-the-art approaches', Journal of Marketing Research, forthcoming.

Monroe, K.B. (1973) 'Buyers subjective perceptions of price', Journal of Marketing Research 10(1): 70-80.

Slovic, P. (1972) 'Psychological study of human judgment: Implications for investment decision making', Journal of Finance 27(4): 779-799.

Slovic, P., Fischhoff, B., Lichtenstein, S., Corrigan, B. and Combs, B. (1977) 'Preference for insuring against probable small losses: Insurance implications', Journal of Risk and Insurance 44(2): 237-258.

Tversky, A. and Kahneman, D. (1974) 'Judgment under uncertainty: Heuristics and biases', Science 185(4157): 1124-1131.

Tversky, A. and Kahneman, D. (1981) 'The framing of decisions and the psychology of choice', Science 211(4481): 453-458.

Tversky, A. and Kahneman, D. (1986) 'Rational choice and the framing of decision', Journal of Business 59(4): S251-S278.

Tversky, A. and Kahneman, D. (1991) 'Loss aversion in riskless choice: A reference-dependent model', Quarterly Journal of Economics 106(4): 1039-1061. 
Tversky, A. and Kahneman, D. (1992) 'Advances in prospect theory: Cumulative representation of uncertainty', Journal of Risk and Uncertainty 5(4): 297-323.

Vanhuele, M. and Drèze, X. (2002) 'Measuring price knowledge shoppers bring to the store', Journal of Marketing 66(4): 72-85.

Völckner, F. (2005) Biases in measuring consumers' willingness to pay, Working Paper on Marketing and Retailing, University of Hamburg.

Völckner, F. (2006) 'Methoden zur Messung individueller Zahlungsbereitschaften: Ein Überblick zum State of the Art', Journal für Betriebswirtschaft 56(1): 33-60.

Wakker, P.P., Thaler, R.H. and Tversky, A. (1997) 'Probabilistic insurance', Journal of Risk and Uncertainty 15(1): 7-28.

Wertenbroch, K. and Skiera, B. (2002) 'Measuring consumers' willingness to pay at the point of purchase', Journal of Marketing Research 39(2): 228-241.

Winkler, R.L., Roodman, G.M. and Britney, R.R. (1972) 'The determination of partial moments', Management Science 19(3): 290-295.

Zimmer, A., Gründl, H. and Schade, C. (2008) Default risk, demand for insurance, and optimal corporate risk strategy of insurance companies, Working Paper, Humboldt-Universität zu Berlin, School of Business and Economics.

Zimmer, A., Schade, C. and Gründl, H. (2009) 'Is default risk acceptable when purchasing insurance? Experimental evidence for different probability representations, reason for default, and framings', Journal of Economic Psychology 30(1): 11-23.

\section{About the Authors}

Nadine Gatzert studied Mathematics and Economics at the University of Ulm, Germany, and at the University of Southern California in Los Angeles, U.S., majoring in Mathematical Finance and Actuarial Science. She received her doctoral degree in 2007 and postdoctoral qualification in 2009 from the University of St. Gallen, Switzerland. Since 2009, she has held the Chair for Insurance Economics at the University of Erlangen-Nürnberg, Germany. Her main research interests include enterprise risk management, financial guarantees, alternative risk transfer and regulation in the financial services industry.

Carin Huber studied Business Administration, Psychology and Art history at the LudwigMaximilians-University of Munich, Germany. She is a PhD candidate in finance at the University of St. Gallen, Switzerland, and works as project manager at the Institute of Insurance Economics, University of St. Gallen, Switzerland. Her main research interests include behavioural insurance, financial decision-making, and financial guarantees.

Hato Schmeiser studied Business Administration at the University of Mannheim, Germany. After his doctoral degree and postdoctoral lecture qualification (Habilitation) in 2003 at the Humboldt-Universität zu Berlin, he was appointed Professor for Insurance and Risk Management at the University of Münster. Since 2005, he has been Chair for Risk Management and Insurance and Managing Director of the Institute of Insurance Economics at the University of St. Gallen. His main research interests include individual financial planning, dynamic financial analysis, risk management and pricing of financial guarantees, life insurance modelling and the regulation of financial firms. 